\title{
Research Paper: The Traffic-Related Readiness of Organizations for Preventing Crisis and Traffic Damages in Metropolitan Areas
}

\author{
Shahriar Behzad Basirat ${ }^{1}$, Davood Doagooyan ${ }^{2 *}$, Gholamreza Shiran ${ }^{3}$, Mousa Amiri $^{2}$
}

1. Shakhes Pajouh Engineering Institute of Natural Hazards, Isfahan, Iran

2. Department of Social Sciences, Amin Police University, Tehran, Iran.

3. Department of Transportation, Faculty of Civil Engineering and Transportation, University of Isfahan, Isfahan, Iran.

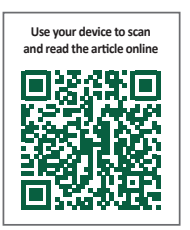

Ctiten: Behzad Basirat Sh, Doagooyan D, Shiran Gh, Amiri M. The Traffic-Related Readiness of Organizations for Preventing Crisis and Traffic Damages in Metropolitan Areas. Health in Emergencies and Disasters Quarterly. 2018; 3(3):151-158. https://doi.org/10.29252/NRIP.HDQ.3.3.151

doi : https://doi.org/10.29252/NRIP.HDQ.3.3.151

Article info:

Received: 16 Jul. 2017

Accepted: 25 Dec. 2017

\section{Keywords:}

Readiness, Traffic-related organizations, Prevention, Traffic crisis, Traffic damages

\begin{abstract}
Background: The first effect of the any natural, artificial and social crises is on the traffic flow and the cut-off of the vital transport arteries. In this effect, various sectors involving in rescue, safety, and evacuation of the wounded and injured people, as well as many decisions made by crisis managers, face a lot of challenges. Therefore, the aim of this study is to investigate the readiness of traffic-related organizations in preventing crisis and traffic damages in metropolitan areas.
\end{abstract}

Materials and Methods: This was an applied study, and the Delphi method was used for collecting the data from respondents. The statistical population consists of 40 Iranian traffic experts. A researcher-made questionnaire was designed for collecting the data, and its validity and reliability were confirmed using Face validity criteria and Cochran's formula $(\alpha=0.891)$. Friedman test was used for statistical analysis, and the goodness of the research model was measured using multiple linear regression analysis.

Results: The readiness to continuously monitor traffic crises (beta coefficients $=0.864$ ) and readiness for timely notification of traffic crises (beta coefficients $=0.399$ ) were reported as the highest effective variables in preventing crisis damages by traffic-related organizations.

Conclusion: To deal with the traffic crises, traffic-related organizations should be ready for continuously monitoring and timely notification of traffic crises, inter-organizational interactions, and mobilization of facilities.

\section{Introduction}

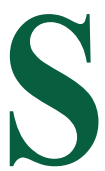

ecurity and peace have been considered as the most influential issues in the formation of societies and their emergence in various historical periods and all human societies. Societies have led to the development of security institutions as well as institutions such as family, education, religion, market, and the government. Crises have been an integral part of the social life, and their number and variety

\section{* Corresponding Author:}

Davood Doagooyan, PhD

Address: Department of Social Sciences, Amin Police University, Tehran, Iran.

E-mail:da.doagooyan@yahoo.com 
have been increasing day by day, and always have had a significant impact on security [1]. Crisis refers to situations featuring severe threat, uncertainty, and sense of urgency. A wide range of phenomena such as natural and technological disasters, conflicts, riots, and terrorist activities are considered as crises.

Traffic-related organizations have a major responsibility in managing various types of crises to reduce damages. In natural, artificial and social crises, the first effect of the crisis is on the traffic flow and the cut-off of the vital transport arteries. In this effect, various sectors involved in rescue, safety, and evacuation of the wounded and injured people, as well as many decisions made by crisis managers, face a lot of challenges. In such situations, due to lack of the proper management and control in this section, the normal life of citizens is disrupted as well as the severity of injuries and damages caused by crises will increase [2]. Since crises have a significant impact on the order and security of the society [3], many crisis management techniques have adopted specific mechanisms to deal with emerging crises. The first step in this way is to know the crisis, dimensions, types, and characteristics of the critical situation, and most importantly, to understand that crises have different stages [4].

Three features of planning, managing, and coping with the crisis of urban traffic reveals the high responsibilities of the urban organizations affecting urban management, in dealing with a variety of crises. This is achieved by providing a model for predicting social crises; if managers are aware of a social crisis before its occurrence and have an operational plan with tactical and strategic guidance groups, they can completely change the situation. Despite the inability of a human being to accurately predict or prevent accidents and disasters such as earthquakes (at least in the present time), it is possible to reduce damages by making appropriate decisions before the crisis. This indicates the importance of further studies in this field. Considering the mentioned issues and given the fact that many regions of Iran are located in the earthquake-prone areas and have experienced other crises such as flood, heavy snowfall and rockfall, planning for special conditions (in addition to normal conditions) and crisis management in protecting critical infrastructure of the country, and most notably, the intercity road network, is necessary.

In recent decades, various studies have been conducted on formation and management of crises with different perspectives and methods. Some researchers have considered case studies and others have conducted comparative studies. Crisis as the result of organizations' undesirable management has also been shown [5]. On the contrary, there are ideas that have considered crisis as an inevitable reality and with a precursor approach in addition to paying attention to the stages of anticipation and prevention, they have adopted coping strategies, emphasized the process of improvement and learning, and considered the process of crisis management along with other effective variables [6]. Attention to traffic damages attracts our attention to a variety of issues including transportation and traffic resulting from various accidents due to damage to the arteries and vital axes of metropolitan cities. Unfortunately, little attention has been given to them. One of the factors contributes to traffic crises is the blockade of arterial road axes in major cities due to traffic congestion. The presence of security, rescue and service forces at the scene of the crisis in the early hours should be facilitated to reduce the damage caused by the crisis. The need for the timely presence of local crisis management forces highlights the need for proper planning in managing traffic crises [2]. Previous national and international studies have also shown the importance of this assessment and planning for controlling the traffic flow network in mitigating the effects of crises, and have provided applied models [7-13].

Pre-planned activities and special conditions in the city sometimes lead to traffic crises. For example, special events, special regional activities, crime-related controls, urban riots, etc. Traffic accidents, long breakdowns of vehicles, car crashes, release of hazardous materials, etc. are among the examples of accidents that lead to traffic crises in the transportation network. In such conditions, the rapid increase in the volume of traffic increased delays, secondary accidents and traffic locks are very likely and predictable factors, and the initial estimate of the amount of damage, especially casualties, is very important. The comprehensive reduction of the vulnerability of traffic and transportation systems to the crises in each country requires the full commitment of the government, organizations, private sectors, and research groups.

\section{Materials and Methods}

This was an applied study where Delphi method was used for gathering data from respondents. The statistical population consists of 40 Iranian traffic managers who had full knowledge of the concepts of research and had sufficient managerial experience in identifying and controlling the damages of traffic crises in major cities. Due to the necessity of obtaining information from the elite, in this study [14], no sampling was conducted. The research variables were divided into four categories of 
Table 1. Damages caused by traffic crises

\begin{tabular}{|c|c|}
\hline Kind of Damage & Examples \\
\hline Human physical damage & $\begin{array}{l}\text { Physical injury, life events and death, widowed women, orphaned children, and } \\
\text { increased physical disability caused by car accidents }\end{array}$ \\
\hline Human psychological \& social damage & $\begin{array}{c}\text { Increased opportunity costs, increased psychological stress, disregarding the } \\
\text { notices of traffic-related organizations, distrust between couples, increased driver } \\
\text { violence, breaking driving laws, Increased social conflicts }\end{array}$ \\
\hline Environmental damage & $\begin{array}{l}\text { Increased environmental pollutants, increased wildlife mortality, Change in } \\
\text { weather conditions, destruction of green space }\end{array}$ \\
\hline Organizational \& managerial damage & $\begin{array}{l}\text { Decline of trust in organizations, increased human and financial costs of organiza- } \\
\text { tions, reduction in employees' incentives to work, tension in inter-organizational } \\
\text { interactions between traffic managers, complexity of traffic plans in controlling } \\
\text { traffic crises, irresponsible and non-institutional decisions of managers, reduction } \\
\text { in organizational commitment of employees, increased organizations' distrust in } \\
\text { managers, irregular relocation rate of managers and employees }\end{array}$ \\
\hline
\end{tabular}

traffic damages including a) human physical damage; b) human psychological \&social damage; c) environmental damage; d) organizational \& managerial damage (Table 1 ), and different ways of traffic-related organizations' readiness against the damage associated with traffic (Table 2). The data collection tool was a researcher-made questionnaire which was validated using Face validity criteria, and its reliability was positively evaluated by the Cochran's formula with a Cronbach's alpha coefficient of 0.891 . Friedman test was used for data analysis, and multiple linear regression analysis was employed to measure the goodness of the research model.

\section{Results}

This article attempts to study the readiness of influential organizations on traffic crises by consulting with experts in this field. According to the presented tests as well as the obtained results, it was found that in the management of traffic crises in Tehran City, coordinated and preplanned presence will have remarkable effect on preventing different harms.

\section{Discussion}

\section{Friedman test results}

The Friedman test results are summarized in Table 3 which shows the ranking of traffic damages suffered by the society. Among studied damages, the human physical damage was reported as the greatest damages of traffic crises according to the study participants, while human psychological and social damage, environmen-

Table 2. Different kinds of traffic-related readiness of organizations against traffic damages

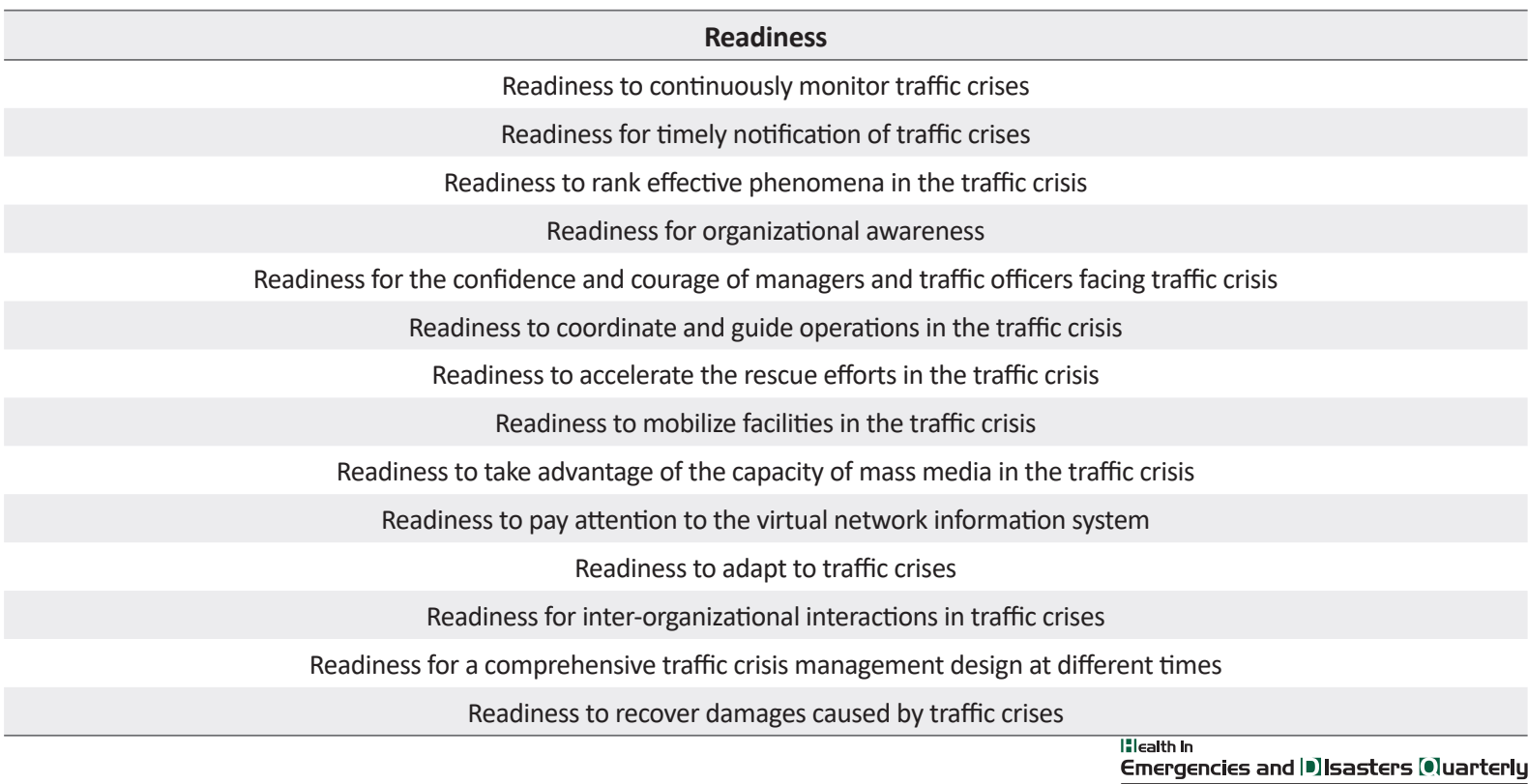


Table 3. Summary of Friedman test results for traffic damages

\begin{tabular}{|c|c|c|}
\hline Rank & Traffic Damages & Mean Rank \\
\hline 1 & Human physical damage & 5.96 \\
\hline 2 & Human psychological \& social damage & 6.87 \\
\hline 3 & Environmental damage & 6.11 \\
\hline 4 & Organizational \& managerial damage & 5.44 \\
\hline
\end{tabular}

Table 4. Summary of Friedman test results for organizational readiness

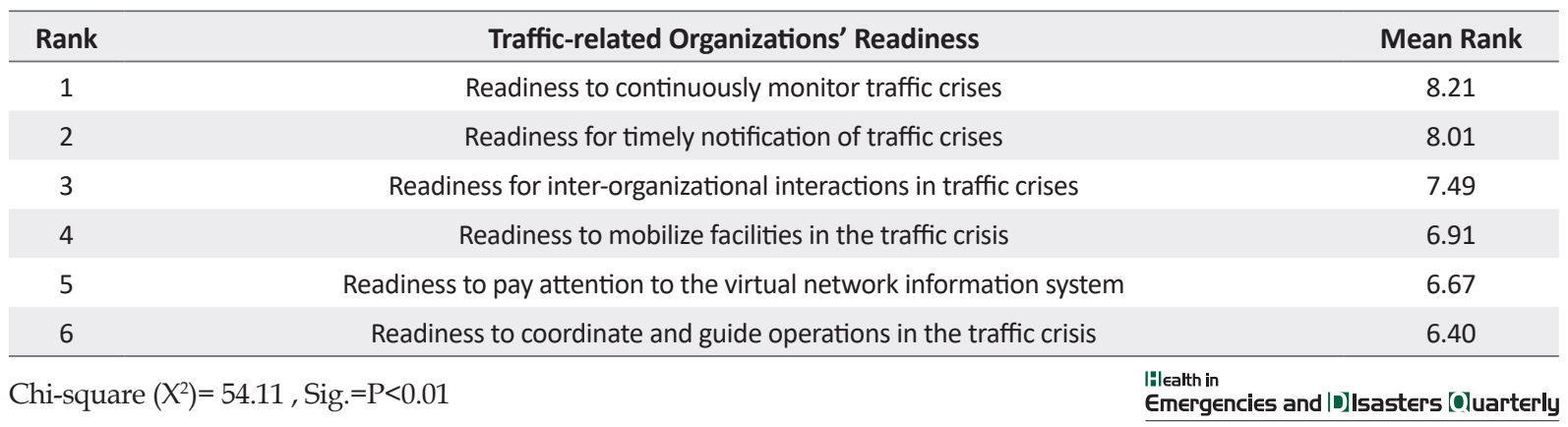

tal damage, and organizational and managerial damage were ranked in two, three and fourth places, respectively.

The test results for evaluating readiness priorities of traffic-related readiness of organizations against traffic crises are summarized in Table 4. According to the results, readiness to continuously monitor traffic crises ranked in first place, while readiness for timely notification of traffic crises, and readiness for inter-organizational interactions in traffic crises were reported as the second and third priority of traffic-related organizations to deal with traffic crises.

\section{Regression test results}

Based on the multiple linear regression model summarized in Tables 5, the coefficient of multiple correlation (R) for the readiness of traffic-related organizations to manage and prevent traffic crises is 0.85 , and the coefficient of determination $\left(\mathrm{R}^{2}\right)$ is 0.723 . This indicates that $\sim 73 \%$ of the readiness variance is controlled by the predictor variables. A constant value $(\alpha)$ is 0.627 , and all variables can affect the research model where readiness to continuously monitor traffic crises and readiness for timely notification of traffic crises with beta coefficients

Table 5. Regression model summary for traffic-related organizations' readiness

\begin{tabular}{cccc}
\hline $\mathbf{R}$ & R Square & Adjusted R Square & Std. Error of the Estimate \\
\hline 0.853 & 0.728 & 0.723 & 0.669 \\
\hline & & & $\begin{array}{c}\text { |lealth in } \\
\text { Emergencies and [D]isasters [Oluarterly }\end{array}$
\end{tabular}

Table 6. Regression coefficients

\begin{tabular}{|c|c|c|c|c|c|}
\hline \multirow[t]{2}{*}{ Variables } & \multicolumn{2}{|c|}{$\begin{array}{l}\text { Unstandardized } \\
\text { Coefficients }\end{array}$} & \multirow{2}{*}{$\begin{array}{c}\begin{array}{c}\text { Standardized } \\
\text { Coefficients }\end{array} \\
\text { Beta }\end{array}$} & \multirow[t]{2}{*}{$\mathbf{t}$} & \multirow[t]{2}{*}{ Sig. } \\
\hline & B & Std. Error & & & \\
\hline (Constant) & 0.627 & 0.181 & & 3.456 & 0.001 \\
\hline Readiness to mobilize facilities in the traffic crisis & 0.213 & 0.063 & 0.211 & 0.005 & 0.049 \\
\hline $\begin{array}{c}\text { Readiness for inter-organizational interactions in traffic } \\
\text { crises }\end{array}$ & -0.270 & 0.055 & -0.258 & -1.486 & 0.039 \\
\hline Readiness for timely notification of traffic crises & 0.410 & 0.050 & 0.399 & 0.433 & 0.021 \\
\hline Readiness to continuously monitor traffic crises & 0.899 & 0.035 & 0.864 & 25.424 & 0.000 \\
\hline
\end{tabular}



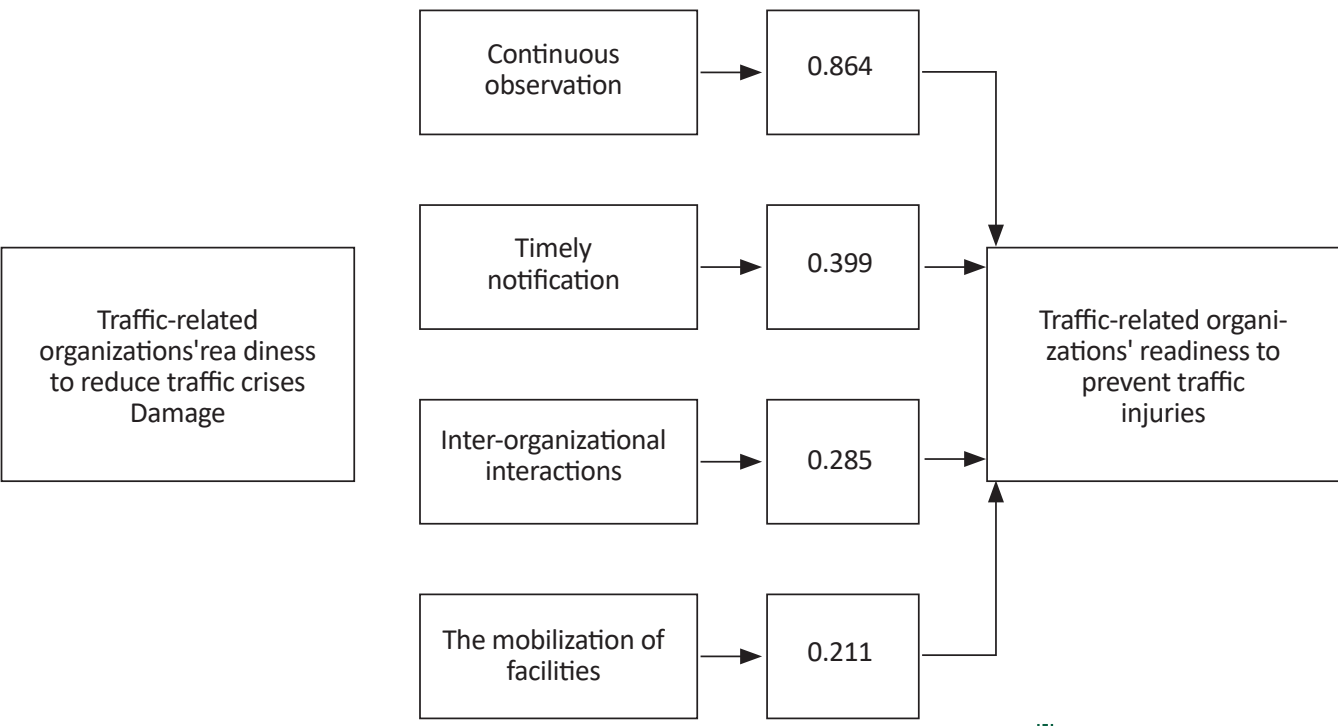

Health in

Figure 1. A research model for traffic-related organizations' readiness against traffic crises

Emergencies and |Disasters [Oluarterly

of 0.864 , and 0.399 , respectively were reported as the highest effective variables (Table 6). Figure 1 shows the research model of traffic-related organizations' readiness in dealing with traffic damages.

\section{Ethical considerations}

The principle of confidentiality of information and informed consent of all participants in this study has been respected. All participants were informed at the beginning of survey that they can stop their participation at any time, without encountering any problems. This paper is extracted from a $\mathrm{PhD}$. thesis belong to Shakhes Pajouh Engineering Institute of Natural Hazards, and all related ethical principles have been applied to this study according to the instructions of this research institute.

\section{Conclusion}

Investigation of documents and traffic data for Tehran demonstrated that the most important part of Tehran's traffic is because of neglecting the use of traffic control patterns in traffic crises. The vast and growing range of crises that threaten the transportation network either directly or indirectly also requires a different response and approach. Accidents and critical cases resulting from such crises are the main reasons for delay and traffic problems in the transportation network. So far, no specific governmental or non-governmental organization has provided a model for managing the traffic crises in Tehran, and there is no single and specific procedure in this field. Despite the fact that in terms of technological equipment, good progress has been made in the field of transportation which can be very effective in emergency transport, but there is no commitment and responsibility from organizations regarding the consequences of poor performance of the emergency transportation system.

As mentioned above, the crisis in transportation is a sudden accident with extensive financial or life-threatening damages requiring urgent actions, or a sudden and growing accident which is followed by an undesirable performance of the transportation network leading to widespread financial or human, psychological, environmental, managerial and organizational losses. In all of the damages, there is a need for urgent actions, and require help and resources beyond the capacity of the responsible organizations to deal with the crisis. In this regard, the prevention of damages caused by the traffic in Tehran depends on planning and has a scientific and purposeful approach. Results of the present study demonstrated that the most important damages caused by the traffic of Tehran are human physical, human psychological and social, and environmental damages, respectively. Any action and preparation of organizations in this field should be based on the prevention of these damages. In this regard, the results of the current study demonstrated that to prevent these damages, traffic-related organizations during the traffic crisis should be prepared in the fields of continuous observation of traffic crises; timely notification of traffic crises; inter-organizational interactions and mobilization of facilities. Among these kinds of organizational readiness, the continuous monitoring of the traffic crisis in Tehran will have the highest effect on reducing the damages caused by the traffic crisis.

We recommend following to reduce the vulnerability of the community from the traffic crisis: Implementing 
the proposed research model. Considering its comprehensiveness and trans-organizationalism from one hand, and the traffic problem of Tehran as a trans-organizational crisis, on the other hand, there is a need for the creation of a trans-organizational firm. This firm not only determines strategies for different organizations but also takes the role of planning, guidance, and control of organizations associated with traffic crises. In this regard, with emphasis on research findings and the importance of the issue of traffic crisis, the head of this leading institution is suggested to be the president and its secretary to be the first vice president.

Considering the importance of traffic-related readiness of organizations to continuously monitor traffic crises in reducing social damages, attention to the data processing system is very important. In this regard, attention should be paid to data on temporal and spatial patterns of traffic crisis prediction, and the organizations related to data production in this area need to take actions. The formation of an institution in the Ministry of Roads and Transportation to produce software for forecasting a traffic crisis can provide the fields of data production. Also, the design and construction of simulation models and forecasting software for traffic crises and modeling the interaction structure of the organization related to the area of traffic crises in line with Iran can be effective in preventing damages from traffic crises.

Holding training courses on the prevention of traffic crisis. Conducting such courses can be effective in employee training, empowerment, motivation, increased organizational endeavors, and awareness of how to support for road traffic crisis victims is accomplished through group and inter-organizational work. In this regard, the publication of books and related pamphlets, educational films, and the use of other countries' experiences in improving training will be effective.

Considering the importance of inter-organizational interactions of traffic-related organizations in reducing the damage from traffic crises in Tehran (and all metropolitan areas), a code of conduct should be set by the highest decision-making authorities to describe the tasks of each educational institutions, such as voice and television, and other effective educational sectors for training the people and the staff of each of the organizations involved in traffic crises. Social media undoubtedly has an important role in informing people. It is suggested that institutions related to traffic crises use these networks effectively to prevent the damage caused by traffic crises in the metropolitan areas.
In addition to the above-mentioned recommendations, the readiness system of traffic-related organizations should be mentioned. In this regard, we recommend the following guidelines: Preventing traffic crises by adopting unit management and cohesive organization systems which should be organized on the basis of consultative meetings of related traffic organizations; By creating communication channels, inter-organizational interactions can be developed to manage the onset of traffic crises. Such channels can be accessed through specified phone lines, satellite phone lines, or online websites. The idea of organizational interactions seems to be effective in conveying information and clarifying the traffic crisis to make comprehensive decisions in this area; The use of highly capable human resources that has a high level of readiness and the ability to rescue people in traffic crises; and Managing the onset of the crisis, force mobilization, and the ability of employees to carry out special operations, which requires inter-organizational coordination, monitoring, and operational control.

The model of traffic crisis prediction management in Tehran developed in this study indicates that the use of this model while reducing human, financial and psychological costs can provide many opportunities for organizations involved in the prevention of traffic crises in Tehran. This model shows that crisis prediction management should first rely on human resources and then on support and organization of forces to manage traffic crises. All managers of traffic-related organizations should be aware that any action taken to deal with the traffic crises should be based on an approved model, such as the model presented in this study.

To advance the goals of future crisis management in Tehran, attention to inter-organizational communication and the use of modern communication channels can be effective in reducing traffic accidents and problems. Assessing human and financial losses in Tehran's traffic crises due to factors such as earthquake and flood. These calculations can be related to pre-crisis transports and the capacities of each of the streets and roads in Tehran. Undoubtedly, such computations should be made by employing well-trained experts and the use of the statistical and mathematical software. The hiring of these people and the production of the software are among the other suggestions of this study.

Carrying out inter-organizational maneuvers with the presence of traffic-related organizations which, while improving collaboration and assistance, provides a platform for wide-ranging organizational cooperation. Praising organizations that had more activities in managing 
traffic crisis and its prevention by the highest authority of the country's executive system. This can help encourage other organizations and provide them with the necessary motivations.

\section{Acknowledgements}

The present paper was extracted from the $\mathrm{PhD}$ thesis of the first author in Shakhes Pajouh Research Institute.

\section{Conflict of Interest}

The authors declared no conflicts of interest.

\section{References}

[1] Pearson CM, Clair JA. Reframing crisis management. Academy of Management Review. 1998; 23(1):59-76. doi: 10.5465/ amr.1998.192960

[2] Esmaeili, A. [Crisis management in the traffic area (Persian)]. Tehran: Police University Press; 2009.

[3] Pour Ezzat A, Damadi SH, Mostafavi Sh, Mottahedin M, Sayyadi Zade A. [Design of the national mobilization system to address natural and social crises (Persian)]. Kamal-e Modiriat. 2004; 4-5:75-110.

[4] Rowshandel A, Purezzat AA, Qolipur A. [A comprehensive model of the crisis management process from the perspective of order and security (Persian)]. Danesh-e-Entezami. 2008; 10(2):60-84.

[5] Meyers GC, Holusha J. Managing crisis: A positive approach. Crows Nest: Unwin Hyman; 1986.

[6] Van Exel NJA, Rietveld P. Public transport strikes and traveller behaviour. Transport Policy. 2001; 8(4):237-46. doi: 10.1016/s0967-070x(01)00022-1

[7] Chang SE, Nojima N. Measuring post-disaster transportation system performance: The 1995 Kobe earthquake in comparative perspective. Transportation Research Part A: Policy and Practice. 2001; 35(6):475-94. doi: 10.1016/s09658564(00)00003-3

[8] Chen R, Sharman R, Rao HR, Upadhyaya SJ. Coordination in emergency response management. Communications of the ACM. 2008; 51(5):66-73. doi: 10.1145/1342327.1342340

[9] Amiri, A. [A research project for investigating nature of natural crises with security/law enforcement approach (Persian)] Tehran: Shahid Beheshti University of Medical Sciences; 2006.

[10] Elahi F, Izadkhah Y. [A plan for reducing the effects and structure of earthquake crisis management in health centers. Proceeding of first scientific and research conference of rescue and aid (2002) (Persian)]. Tehran: Helal-e-Iran Applied Science Higher Education Institute; 2004.

[11] Adeli A. [The evaluation of I. R. of Iran's police performance in restoring law, order and security in the city of Bam:
With reference to the approach of crisis management (Persian)]. Modiriat-E-Entezami Research Journal, 2012; 7(2):25381.

[12] Mir Habibi H, Momeni A. [The role of police in crisis management (A case study of Bam earthquake) (Persian)]. Danesh-E-Entezami, 2015; 14(14):138-67.

[13] Cheshmberah, M., Karbasian, M., Yavari, A. [Phase oriented model of police logistics management in the management of natural disasters (Persian)]. Joghrafiyay-E-Entezami Research Journal, 2014; 2(8):129-54.

[14] Ahmadi N. [Introduction and review of Delphi method (Persian)]. Olome Ejtemaei, 2009; 22:100-8. 
